\title{
Binary Logistic Regression Model for Assessing Factors Associated with Nutritional Status of Children Under Five Years among Chepang Community in Siddi, Chitwan, Nepal
}

\author{
Ravi Kiran Poudel ${ }^{* *}$ and Shankar Prasad Khanal ${ }^{2}$
}

Submitted: 09 September 2020; Accepted: 19 October 2020

Published online: 18 December 2020

DOI: https://doi.org/ / 0.3 | 26/njs.v4i0.3345 I

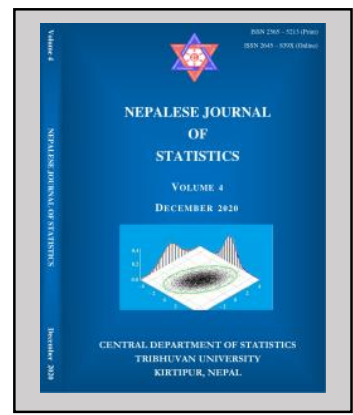

\section{ABSTRACT}

Background: Chepang Community in Nepal has often been characterized as the poorest among Nepal's poor, and has faced food insecurity at a household level each year. Health status of their children is poor compared to other community children and more so for the age group under the age of five years.

Objective: To find the proportion of stunting, wasting and underweight, and to assess the most promising factors associated with the nutritional status of children under five years of Chepang community in Siddi, Chitwan, Nepal.

Materials and Methods: A cross-sectional research design was used with 170 samples. To find the association of different factors with the nutritional status of children under 5 years of age (stunting, wasting and underweight, each) binary multiple logistic regression model was used and the goodness of fit of the model was assessed through Hosmer and Lemeshow test.

Results: The overall proportion of children under five years of the Chepang community is $60.6 \%$, $30.6 \%$ and $44.7 \%$ for underweight, stunting and wasting respectively. Among many factors, the mother's illiteracy (OR: $5.30,95 \% \mathrm{Cl}: 1.37$ to 21.57 ), external monthly family income (s NRs. 2000) (OR: $9.65,95 \% \mathrm{Cl}: 3.23$ to 30.78 ) and food availability for six months from own land (OR: $4.17,95 \% \mathrm{Cl}$ : 1.90 to 17.98) have a significant association with underweight. Similarly, for stunting, female child (OR: $2.19,95 \% \mathrm{Cl}: 1.02$ to 4.70 ), number of children (more than one) below 14 years at home (OR: $4.15,95 \% \mathrm{Cl}:$ : .77 to II .04) and external family income (S NRs. 2000) (OR: 4.42, $95 \% \mathrm{Cl}$ : 1.01 to 17.06 ) are significantly associated, and for wasting, a number of children (more than one) below 14 years at home (OR: $4.64,95 \%$ of $\mathrm{Cl}$ : I.7I to 12.60) and external family income (S NRs. 2000) (OR: $5.17,95 \%$ Cl: 2.27 to II.79) are significantly associated.

Conclusion: Substantial numbers of children from Chepang community are having the problem of underweight, stunting and wasting. Different demographic and socio-economic variables have been found associated for odds of having low level of nutritional status of children.

Keywords: Logistic regression, nutritional status, stunting, underweight, wasting. 
Address correspondence to the author: Central Department of Statistics, Institute of Science and Technology, Tribhuvan University, Kirtipur, Nepal. E-mail pabanpoudel99@gmail.com ${ }^{\text {** }}$ (corresponding author email); drshankarcds@gmail.com²

\section{INTRODUCTION}

The Chepang are an indigenous Tibeto-Burman people group mainly inhabiting the rugged ridges of the Mahabharat mountain range of central Nepal. The Chepang has often been characterized as the poorest of Nepal's poor. The Chepang community has faced food insecurity at a household level every year. They often do not have enough food to eat. They normally rely on cereal crops for about six months and for the other months; they depend on wild resources and work as laborers for subsistence. Wild foods make up almost 40 percent of the overall diet of the Chepangs (Shah, 2014). Malnutrition refers to deficiencies, excesses, or imbalances in a person's intake of energy and/or nutrients. The term malnutrition addresses three broad groups of conditions: under nutrition, which includes wasting (low weight-for-height), stunting (low height for-age) and underweight (low weight-for-age) (WHO, 20I7). Malnutrition is the biggest risk factors for the global burden of disease; every country is facing a serious public health challenge from malnutrition. The economic consequences represent losses of II percent of gross domestic product (GDP) every year in Africa and Asia, whereas preventing malnutrition delivers $\$ 16$ in returns on investment for every $\$$ I spent (IFPRI, 20I6).

More than one-third (36\%) of children under five years in Nepal were stunted, or too short for their age. Stunting was more common in rural children (40\%), compared to urban children (32\%). Overall, $10 \%$ of children were wasted (too thin for height), a sign of acute malnutrition. In addition, $27 \%$ of children were underweight or too thin for their age ( $\mathrm{MOH}, 2017)$. In Nepal, one in every twenty-one children died before reaching the age of one year, while one in every sixteen did not survive to their fifth birthday. In Chitwan, Gorkha and Dhading districts combined 17\% children of Chepang had better height, weight and thickness of arm than other communities' children (Ghimire, 2015). The nutritional status of children under five years of Nepal based on previous literature is seeming extremely poor, so we can say that the children's of Chepang community are also not the exception in this regard. In order to determine a child's nutritional status, it needs to compare the child's status with a reference for healthy children. References are used to compare a child's measurement(s) with the median for children of the same sex and age for height-for-age and weight-for-age or to children of the same sex and height for weight-forheight). The WHO adopted the National Centre for Health Statistics, Centre for Disease Control and Prevention, US reference curves for international use. Evidence has shown that the growth patterns of well-fed, healthy pre-school children from diverse ethnic backgrounds are similar and consequently are applicable for children of all races and ethnicities. This is the preferred expression for anthropometric indicators in surveys. It is the difference between the value for an individual 
and the median value of the reference population for the same age or height, divided by the standard deviation of the reference population. In other words, by using the Z-score (shown in equation I), one will be able to describe how far a child's weight is from the median weight of a child at the same height in the reference value (WFP, 2005).

$$
\text { Z-score }=\frac{\text { Measured value }- \text { Median of reference population }}{\text { Standard deviation of reference population }}
$$

This study is an attempt to assess the significant factors associated with the nutritional status of children less than five years of age among Chepang community residing in selected wards ( 10 and II) of Kalika municipality, Chitwan among different factors through appropriate statistical modeling.

\section{MATERIALS AND METHODS}

\section{Data and study area}

Chitwan is one of 77 districts of Nepal, and is located in the southwestern part of Bagmati Province. Kalika municipality is one of the municipalities of the Chitwan district. The study area is the ward no. 10 and II (Siddi) of Kalika Municipality, Chitwan, Nepal. Siddi is a place of residence of indigenous people especially for Chepang community. According to the then record of Kalika municipality the population size of Chepang in Siddi was 3,332 (87\% of total population of the wards).

The number of children below five years in the area of the study (Kalika municipality ward 10 and I I, Siddi) was 523 which was recorded in Primary Health Post, Siddi. Among them, 33 children were not from Chepang community, and these were excluded from the study, and finally the lists of 490 children were taken as population for the study. The prevalence of underweight for children under five years was $22 \%$ of overall children's in Padampur, Kalika municipality (Ruwali, 2018). The sample size 170 out of total 490 children was finalized through the sample size calculation formula (Cochran, 1977) using the prevalence of 0.22 with $95 \%$ confidence level. These samples were selected by using simple random sampling without replacement method, and the random serial number of required subjects were made by using MS Excel. A request letter for the permission of data collection was submitted to Kalika Municipality and Primary Health Post, Siddi. Data was collected from third week of March 2018 and ended within 12 days. The average time required for collecting information from one respondent was approximately 20 to 40 minutes. A questionnaire was used for gathering information on various topic related to children under five years of Chepang community. The questionnaires were adopted from the manual to measure malnutrition of World Food Program (WFP, 2005) with some modifications keeping in view to address the objectives of the study. For this purpose the mother of a child or head of family was interviewed and a questionnaire was filled by the researcher and the enumerators. The height of children under two years was measured by lying down on the board (recumbent height) and standing height was measured for all other children by centimeter tape. Measurement of the weight of children was done by using electronic weighting machine. 


\section{Study variables}

Underweight, stunting and wasting each was dependent variable. Independent variables were classified into socio-demographic, socio-economic, maternal and child care, nutritional and environmental variables. Socio- demographic variables include age (in months), gender, family size, number of children, birth order, father's and mother's literacy, mother's age at child birth and at first marriage. Socio-economic variables include external monthly family income (excluding agricultural income) and food availability. Maternal and child care variables include place of delivery, ANC visits, disease status of children and vaccination status. Nutritional variables include current breast feeding status and breast feeding time. In environmental variables toilet availability at home, water type and hand washing behavior were included. These variables were identified through the extensive review of literature and consultations with the relevant experts (Gharti Chhetri, 2005; WHO, 2009; CBS, 20II; $\mathrm{MOH}, 2017$ ).

\section{Data analysis procedure}

For the analysis of nutritional status of children, weight and height of children was measured, and then Z- score was calculated. The Z-score related to stunting (HAZ- Height for Age Z-score), wasting (WAZ- Weight for Height Z-score), and underweight (WHZ-Weight for Age Z-score) is obtained by using reference population according to National Centre for Health Statistics, Centre for Disease Control and Prevention, US(WHO, 2009). Nutritional Status is characterized by Stunting, Wasting and Underweight.

- Stunting: Height for Age Z-score < -2 SD of the WHO Growth Standards median.

- Wasting: Weight for Height Z-score < -2 SD of the WHO Growth Standards median.

- Underweight: Weight for Age Z-score < -2 SD of the WHO Growth Standards median

Where SD stands for standard deviation.

Data are presented through frequency table, mean, standard deviation and cross tabulations as per their suitability as descriptive statistics. In order to assess the association of each independent variable with each outcome variable, Chi-square test as a bivariate analysis, was used, through which the candidate variables for multiple logistic regression model was identified. Results were considered statistically significant if $p$-value $<0.05$ at $5 \%$ level of significance. Data were analyzed using Statistical Package of Social Sciences (IBM SPSS) version 20.

\section{Statistical model}

As the outcome variable of interest here is dichotomous, binary multiple logistic regression model was applied. Since there were three outcome variables (stunting: Yes vs. No; Wasting: Yes vs. No, and Underweight: Yes vs. No), three separate binary multiple logistic regression models with candidate variables identified from bivariate analysis were applied to identify the most important factors associated with each outcome. 
The outcome variable $y_{i}$ is defined as follows.

$$
y_{i}=\left\{\begin{array}{l}
0, \text { if the outcome is 'no' } \\
1, \text { if the outcome is 'yes' }
\end{array}\right.
$$

Let $x_{1}, x_{2}, \ldots \ldots, x_{k}$ be $k$ independent variables, which may be discrete or continuous or combination of both.

Mathematical model of binary multiple logistic regression model is as follows.

$$
g(x)=\ln \left[\frac{\pi(x)}{1-\pi(x)}\right]=\beta_{0}+\beta_{1} x_{1}+\beta_{2} x_{2}+\ldots .+\beta_{p} x_{k}
$$

where, $\pi(x)=\frac{\exp \left(\beta_{0}+\beta_{1} x_{1}+\beta_{2} x_{2}+\ldots .+\beta_{p} x_{k}\right)}{1+\exp \left(\beta_{0}+\beta_{1} x_{1}+\beta_{2} x_{2}+\ldots .+\beta_{p} x_{k}\right)}$, notations have usual meanings.

The values of the parameters were estimated by solving maximum likelihood equations using iterated weighted least square procedure (Hosmer \& Lemeshow, 2000). The model yielded the odds ratio $(O R)$ and same has been reported for each independent variable in the final multiple logistic regression model.

\section{Test of overall significance of the regression coefficients}

In order to test the overall significance of explanatory variables in the final multiple logistic regression model, the log- likelihood ratio test based on the model with all the independent variables and the model with only intercept term has been used. The log likelihood ratio follows Chi-square distribution with $k$ degrees of freedom (where $k$ denotes the number of covariates in the model. It is computed as follows.

$$
\begin{aligned}
-2 \log \left[\frac{\mathrm{L} 0}{\mathrm{~L} 1}\right] & =-2\left[\log \left(\mathrm{L}_{0}-\mathrm{L}_{1}\right)\right] \\
= & -2\left[\mathrm{~L}_{0}-\mathrm{L}_{1}\right]
\end{aligned}
$$

where $L_{0}=$ Likelihood function of the model without any covariate; $L_{1}=$ Likelihood function of the full model.

\section{Goodness of fit of the model}

In order to test the goodness of fit of the fitted binary multiple logistic regression model, among, different tests, Hosmer and Lemeshow test (Hosmer \& Lemeshow, 1980) which measure the correspondence between the actual and predicted values of the dependent variable, has been applied. This test is a commonly used for test of assessing the goodness of fit of a model and allows for any number of independent variables. The model fit is indicated by a smaller difference in the observed and predicted classification or a large p-value (higher than 0.05 for $5 \%$ level of significance). It works in similar manner as chi-square test of goodness of fit.

\section{$R^{2}$ - statistics}

The variation of dependent variable due to the variation in independent variables in binary multiple logistic regression model has been explained by the coefficient of determination based on 
the likelihood, the technique proposed by Nagelkerke (I99I). In this research work too, the Nagelkerke $\mathrm{R}^{2}$ has been computed and reported.

\section{RESULTS}

Study consists of I 70 children overall, among them 75 (44.I \%) of them are males and 95 (55.9 $\%)$ of them are females. This study consists of 19 (II.2\%) children of age group 0 to II months, $64(37.6 \%)$ children of age group 12 to 35 months and 87 (5I.2\%) children of age group 36 to 59 months of the total 170 children. The average age of children is 36.56 months with standard deviation of 17.62 months. Among all the mothers, 39 (22.9 \%) mothers have got married below 15 years, 77 (45.3\%) of mothers have got married between age I 5 to 17, 47 (27.6\%) mothers have got married between age 18 to 20 years and remaining 7 (4.1\%) of mothers have got married over age 20. The mean and median age of marriage in Chepang community women is reported to be 16.44 years and 16 years respectively with a maximum of 23 years and a minimum of 9 years. Study shows $12.4 \%$ and $17.1 \%$ of the children's fathers and mothers are illiterate respectively. Twenty percent of the children's father and $12.9 \%$ of the children's mothers have studied secondary education and more. Among all, only $22.4 \%$ of family have food available for less than 6 months from their own land. The average duration of food availability is about nine and half months per year from the own land of the family. In this community more than half of the child deliveries were taken place at the home with mostly untrained human resource. Out of total 170 delivery of the children, 109 (64.1 \%) of delivery took place at home. Study shows that just $28.2 \%$ of the mothers have four and more Ante natal check-up (ANC) visits at the pregnancy period and $9.4 \%$ of the mothers did not take at least a single ANC visit at pregnancy period. The status regarding five common diseases (Typhoid fever / Jaundice / Diarrhea / Acute respiratory disease / others etc) in the age group of under five-year children in the context of Nepal was asked through the survey questionnaire, the response provided by children's mother was considered but not based on the clinical observation during the survey. About $65 \%$ of the children under study might get affected by at least one disease (Typhoid fever / Jaundice / Diarrhea / Acute respiratory disease / others) in the last one year period. The percentage of low weight born children is 34.I. The proportion of different nutritional status of children is presented in Table I.

Table I. Distribution of nutritional status of children.

\begin{tabular}{ll}
\hline Status & Number $(\%)$ \\
\hline Underweight & $103(60.6)$ \\
Stunting & $52(30.6)$ \\
Wasting & $76(44.7)$ \\
\hline
\end{tabular}

The percentage of underweight is reported to be the highest 60.6 (WAZ below -2SD) followed by the percentage of wasting is 44.7 ( $\mathrm{WHZ}$ below -2SD) and then the percentage of stunting is 30.6 (HAZ below -2SD). The percentage to have some form of malnutrition (underweight, stunting and wasting) is $7 \mathrm{I} .2$ for the children under five years of Chepang community 
in Siddi, Chitwan, Nepal. The percentage of underweight, stunting and wasting is higher in the age group of 12-35 months and lower in 0-I I months and 36-59 months age group of children (Figure I).

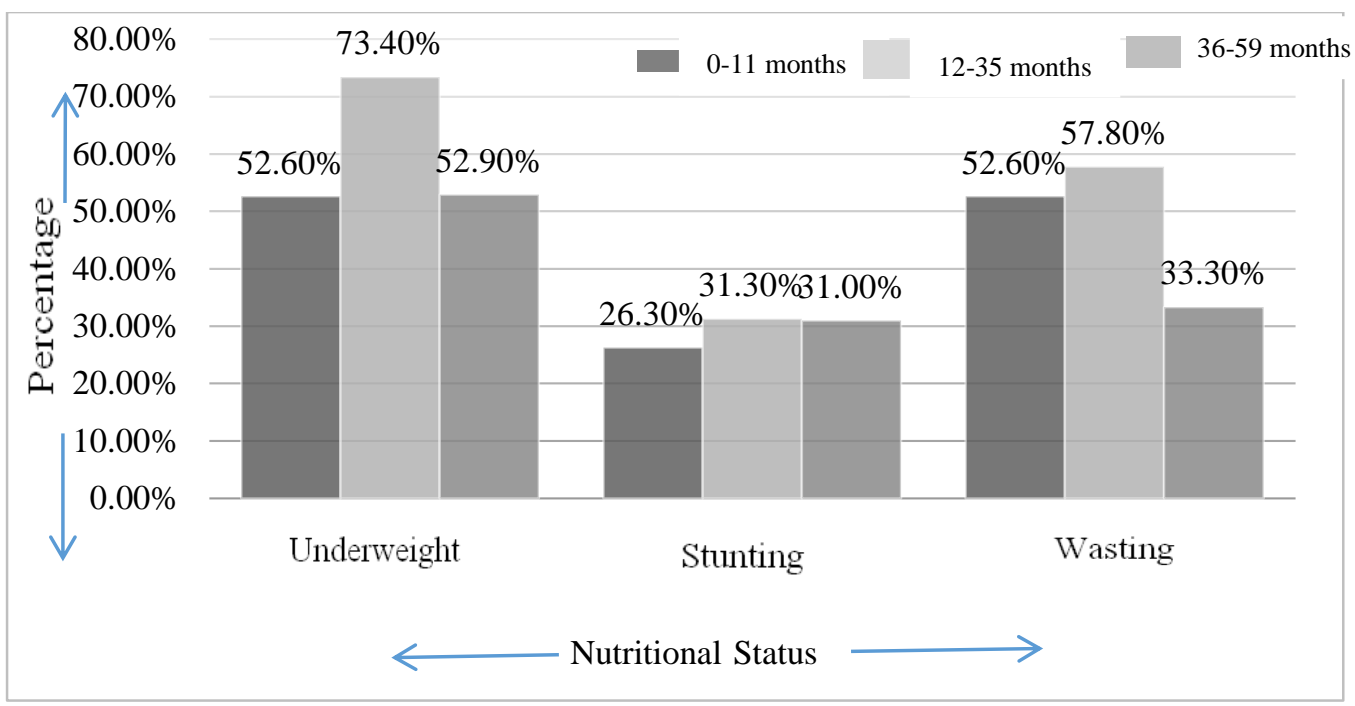

Fig. I. Children's nutritional status in different age group (in year).

Independent variables such as father's literacy, mother's literacy, income of the family, food availability, ANC visits, disease status, toilet availability and hand washing each has significant association with underweight in bivariate analysis (Table 2). Similarly, gender of children, family size, number of children below fourteen years, mother's literacy, income of the family, ANC visits, disease status and hand washing are significantly associated with stunting in bivariate analysis. For outcome variable wasting, father's and mother's literacy, number of the child below 14 years, monthly income of the family, disease status of a child, balance diet, hand washing status and availability of toilet are significant explanatory variables through bivariate analysis (Table 2). Finally, external family income (> NRs. 2000 vs. S NRs. 2000), mother's literacy (Illiterate vs. Literate), disease status (No vs. Yes) and hand washing behavior (No vs. Yes) are the common independent significant factor associated with each underweight, stunting and wasting (Table 2). 
Table 2. Bivariate analysis of variables with underweight, stunting and wasting.

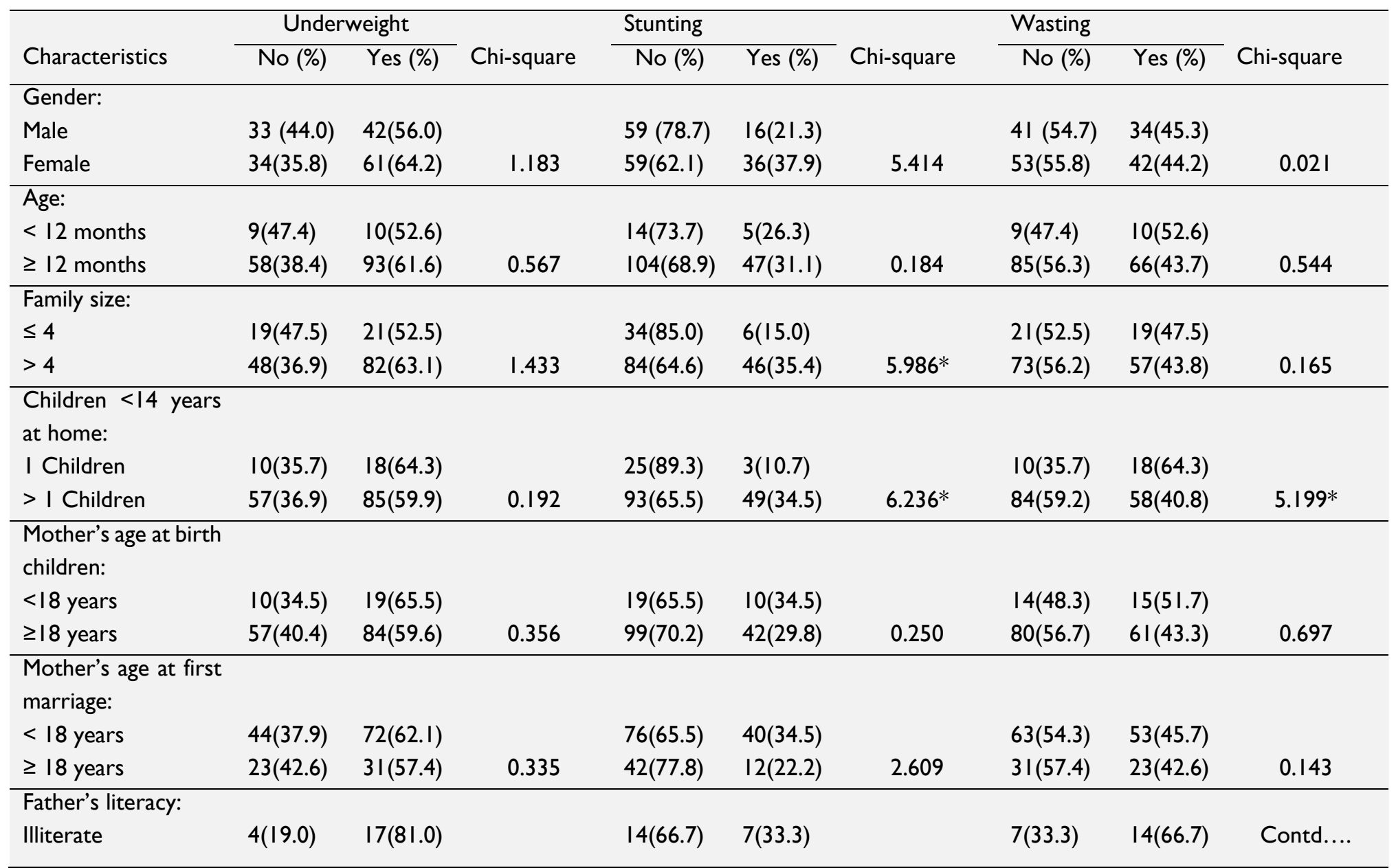




\begin{tabular}{|c|c|c|c|c|c|c|c|c|c|}
\hline Literate & $63(42.3)$ & $86(57.7)$ & $4.161 *$ & I04(69.8) & $45(30.2)$ & 0.085 & $87(58.4)$ & $62(4 I .6)$ & $4.674^{*}$ \\
\hline \multicolumn{10}{|c|}{ Mother's literacy: } \\
\hline Illiterate & $\mathrm{I}(3.2)$ & $30(96.8)$ & & I5(48.4) & $16(51.6)$ & & |3(4|.9) & $18(58.1)$ & \\
\hline Literate & $66(47.5)$ & $73(52.5)$ & $20.79 * *$ & $103(74.1)$ & $36(25.9)$ & $7.893 *$ & $81(58.3)$ & $58(4 I .7)$ & $2.737^{*}$ \\
\hline \multicolumn{10}{|c|}{$\begin{array}{l}\text { External monthly } \\
\text { family income: }\end{array}$} \\
\hline$\leq$ NRs. 2000 & $19(20.0)$ & $76(80.0)$ & & $56(58.9)$ & $39(4 I .1)$ & & $44(46.3)$ & $5 I(53.7)$ & \\
\hline > NRs. 2000 & $48(64.0)$ & $27(36.0)$ & I I $3.56 * *$ & $62(82.7)$ & $13(17.3)$ & $|6.48|^{* *}$ & $50(66.7)$ & $25(33.3)$ & $25.47 \mid * *$ \\
\hline \multicolumn{10}{|c|}{ Food availability: } \\
\hline$<6$ months & $\mathrm{I}(8.3)$ & I I(9I.7) & & $10(83.3)$ & $2(16.7)$ & & $6(50.0)$ & $6(50.0)$ & \\
\hline$\geq 6$ months & $66(4 I .8)$ & $92(58.2)$ & $5.222^{*}$ & $108(68.4)$ & $50(31.6)$ & I. 179 & $88(55.7)$ & $70(44.3)$ & 0.146 \\
\hline \multicolumn{10}{|l|}{ ANC visits: } \\
\hline 2 visits & $26(28.3)$ & $66(71.7)$ & & $56(60.9)$ & $36(39.1)$ & & $48(52.2)$ & $44(47.8)$ & \\
\hline$>2$ visits & $4 I(52.6)$ & $37(47.4)$ & $|0.44| * *$ & $62(79.5)$ & $16(20.5)$ & $6.891 *$ & $46(59.0)$ & $32(41.0)$ & 0.790 \\
\hline \multicolumn{10}{|l|}{ Disease status: } \\
\hline No & $36(61.0)$ & $23(39.0)$ & & 47(79.7) & $12(20.3)$ & & $39(66.1)$ & $20(33.9)$ & \\
\hline Yes & $3 I(27.9)$ & $80(72.1)$ & $17.664^{* *}$ & $7 I(64.0)$ & $40(36.0)$ & $4.47 \mid *$ & $55(49.5)$ & $56(50.5)$ & $4.270 *$ \\
\hline \multicolumn{10}{|c|}{ Toilet availability: } \\
\hline No & $12(19.7)$ & $49(80.3)$ & & $39(63.9)$ & $22(36.1)$ & & $26(42.6)$ & $35(57.4)$ & \\
\hline Yes & $55(50.5)$ & $54(49.5)$ & I $5.524^{* *}$ & $79(72.5)$ & $30(27.5)$ & 1.344 & $68(62.4)$ & $4 I(37.6)$ & $6.179 *$ \\
\hline $\begin{array}{l}\text { Hand } \\
\text { behavior: }\end{array}$ & & & & & & & & & \\
\hline No & $13(17.8)$ & $60(82.2)$ & & $44(60.3)$ & $29(39.7)$ & & $33(45.2)$ & $40(54.8)$ & \\
\hline Yes & $54(55.7)$ & $43(44.3)$ & $25.006 * *$ & $74(76.3)$ & $23(23.7)$ & $5.031 *$ & $6 I(62.9)$ & $36(37.1)$ & $5.268^{*}$ \\
\hline
\end{tabular}

* Significant at $5 \%$ level of significance, **significant at I\% level of significance. 
The results of multiple logistic regression model for each outcome variable is presented in Table 3. Mother's literacy, monthly family income and food availability are significant independent variables in the fitted multiple logistic regression model for weight for age (underweight).

Table 3. Results of multiple logistic regression model for underweight, stunting and wasting.

\begin{tabular}{|c|c|c|c|c|c|c|c|c|c|}
\hline \multirow{3}{*}{ Characteristics } & \multicolumn{3}{|c|}{ Underweight } & \multicolumn{3}{|c|}{ Stunting } & \multicolumn{3}{|c|}{ Wasting } \\
\hline & \multirow[t]{2}{*}{ OR } & \multicolumn{2}{|c|}{$95 \% \mathrm{Cl}$ for OR } & \multirow[t]{2}{*}{ OR } & \multicolumn{2}{|c|}{$95 \% \mathrm{Cl}$ for OR } & \multirow[t]{2}{*}{ OR } & \multicolumn{2}{|c|}{$95 \% \mathrm{Cl}$ for OR } \\
\hline & & Lower & Upper & & Lower & Upper & & Lower & Upper \\
\hline \multicolumn{10}{|l|}{$\begin{array}{l}\text { External family } \\
\text { income: }\end{array}$} \\
\hline > NRs. 2000 & $9.6^{* *}$ & 3.22 & 30.77 & $4.4 I^{*}$ & 1.79 & 11.04 & $5.17^{*}$ & 2.27 & 11.79 \\
\hline \multicolumn{10}{|l|}{$\leq$ NRs. 2000} \\
\hline \multicolumn{10}{|l|}{$\begin{array}{l}\text { Number of } \\
\text { children < I4 } \\
\text { years at home: }\end{array}$} \\
\hline $\begin{array}{l}\text { I Children } \\
\text { > I Children }\end{array}$ & - & - & - & $4.15^{*}$ & I.0I & 17.06 & $4.64^{*}$ & 1.71 & 12.60 \\
\hline \multicolumn{10}{|l|}{ Mother's } \\
\hline \multicolumn{10}{|l|}{ literacy: } \\
\hline Literate & $5.3^{*}$ & 1.37 & 21.56 & - & - & - & - & - & - \\
\hline \multicolumn{10}{|l|}{ Illiterate } \\
\hline \multicolumn{10}{|l|}{ Food } \\
\hline \multicolumn{10}{|l|}{ availability } \\
\hline (months): & $4.1^{*}$ & 1.90 & 17.98 & - & - & - & - & - & - \\
\hline \multicolumn{10}{|l|}{$\geq 6$ months } \\
\hline \multicolumn{10}{|l|}{$<6$ months } \\
\hline \multicolumn{10}{|l|}{ Gender: } \\
\hline \multicolumn{10}{|l|}{ Male } \\
\hline Female & - & - & - & $2.18^{*}$ & 1.02 & 4.70 & - & - & - \\
\hline
\end{tabular}

* Significant at $5 \%$ level of significance, ${ }^{* *}$ significant at I\% level of significance

Those children whose mother were illiterate have 5.3 times ( $95 \% \mathrm{Cl}$ : 1.37 to 21.57 ) more likely to have underweighted as compared to children whose mother were literate. The children are 9.6 times more likely ( $95 \% \mathrm{Cl}: 3.22$ to 30.78 ) to have underweight whose family have external income up to Rs 2000 compared to those children whose family have external income more than Rs 2000 . Also, those children whose family have food availability up to five months have 4.1 times ( $95 \% \mathrm{Cl}: 1.90$ to 17.98) more likely to have underweight as compared to children whose family have food availability more than 5 months. 
Family income, gender and number of children below 14 years at home are significant in the fitted logistic regression for the outcome variable height for age (stunting). The odds of having children stunted is 2.18 times ( $95 \% \mathrm{Cl}: 1.02$ to 4.70$)$ more for the female children as compare to male children (Table 3 ). The results clearly show that monthly external family income is the common factor for each underweight, stunting and wasting. The number of children below 14 years at home has become common factor for each stunting and wasting only. In logistic regression model for the outcome wasting, number of children below 14 years at home in addition to the family income are significant ( $\mathrm{p}$-value $<0.05)$. The odds of wasting is 4.64 times $(95 \% \mathrm{Cl}$ : I.7I to 12.60) more to the children who have two or more than two children below fourteen years as compared to having only one child (Table 3 ).

The details of test of overall significance of each developed multiple logistic regression model, $\mathrm{R}^{2}$ statistic and Hosmer Lemeshow test are presented in Table 4. The $\mathrm{p}$-value less than 0.05 by Omnibus test of statistics indicates that the overall model coefficients are significant in each model. According to Neglekere $\mathrm{R}^{2}, 31 \%, 8 \%$ and $6 \%$ of the total variation in dependent variable has been explained by the regression model through independent variables in terms of log likelihood for model of underweight, stunting and wasting respectively. The value of $R^{2}$ in each model seems to be low as compared to the value of $\mathrm{R}^{2}$ computed in the fitting of multiple linear regression model. The lower value of $R^{2}$ is expected in logistic regression model (Hosmer \& Lemeshow, 2000) as it is measured based on log likelihood.

Table 4. Test statistics with different model (underweight, stunting and wasting, each).

\begin{tabular}{|c|c|c|c|c|c|c|}
\hline \multirow{2}{*}{$\begin{array}{l}\text { Test } \rightarrow \\
\text { Model for } \\
\downarrow\end{array}$} & \multicolumn{2}{|c|}{ Omnibus test } & \multirow{2}{*}{$\begin{array}{c}\text { Negalkarke } \\
\mathrm{R}^{2}\end{array}$} & \multicolumn{3}{|c|}{ Hosmer and Lemeshow test } \\
\hline & $\begin{array}{c}\text { Chi-square } \\
\text { value }\end{array}$ & d. f. & & $\begin{array}{c}\text { Chi-square } \\
\text { value }\end{array}$ & d. f. & P-value \\
\hline Underweight & $43.66^{* *}$ & 3 & 0.31 & 6.50 & 8 & 0.54 \\
\hline Stunting & $\left.10.5\right|^{*}$ & 3 & 0.08 & 8.59 & 8 & 0.35 \\
\hline Wasting & $7.41^{* *}$ & 2 & 0.06 & 5.48 & 8 & $0.7 I$ \\
\hline
\end{tabular}

* Significant at $5 \%$ level of significance, **significant at $1 \%$ level of significance.

By Hosmer and Lemeshow test, there is no significance difference between the observed and predicted values in each model since $p$-value for each model is $>0.05$ at $5 \%$ level of significance indicating that the goodness of fit of each model has not been violated (Table 4). There is no multicollinearity (VIF below 2.4I) between independent explanatory variables for stunting, wasting and underweight, each in binary multiple logistic regression model.

\section{DISCUSSION}

Among 170 children under five years of the Chepang community $60.6 \%$ are underweighted, $30.6 \%$ are stunted and $44.7 \%$ are wasted. The problem of underweight, wasting and stunting are higher for female children as compared to male children in Chepang community below five years. 
There is not problem of overweight in this community at all. As compare to findings of NDHS, 2016 the percentage of underweight, stunting and wasting $(27 \%, 36 \%$ and $10 \%)$ of Nepal under five years is lower than Chepang community children. Ghimire (2014) had reported in Chitwan, Gorkha and Dhading districts combined 17\% children of Chepang under five years had better nutritional status whereas our study has indicated 29\% Chepang's children has better nutritional status. Comparing the findings of our study and the findings reported by Ghimire (20I4) in the better form of the nutritional status, Chepang Children in Siddi have slightly better position in overall nutritional status.

Wealth quintile and mothers education $(\mathrm{MOH}, 2017)$, size of the family (Pokhrel, Parajuli \& Acharya, 2018), wealth index, size of the child at birth, ANC checkups, education, and sex of a child (Upadhyay \& Bhusal, 2017) were significant variables for determining the Nutritional status of Children under 5 years. In this study, external family income (wealth index related factor), gender, number of children below 14 years at home and mother's literacy are significant for nutritional status of children in Chepang community, this leads that the determining factors for nutritional status under five years of age are similar in Chepang community and in other communities' children of Nepal.

\section{CONCLUSION}

The study concludes that considerable number of children from Chepang community are having the problem of underweight, stunting and wasting. Different demographic and socioeconomic factors are the important determinants associated for having low level of nutritional status of children. Necessary initiatives have to be taken by the concerned authorities in order to improve the nutritional status of Chepang children.

\section{CONFLICT OF INTEREST}

The authors declare that there is no conflict of interest.

\section{ACKNOLEDGEMENTS}

Authors would like to express sincere gratitude to all the faculties of Central Department of Statistics, TU who had provided support to complete this research work. Mr. Prakash Chaudhary, HA, and Miss Kumari Khadka, ANM for their active involvement, and Miss Rachana Ghimire for her moral support during the study, should also be thanked. We are grateful to the anonymous reviewers for their critical comments and suggestions to improve the paper.

\section{REFERENCES}

Central Bureau of Statistics (201 I). Nepal Living Standard Survey 2010/20 I I. Statistical report, Volume II. Kathmandu: CBS.

Cochran, W.G. (1977). Sampling Techniques, $3^{\text {rd }}$ Ed., New Delhi India: Wiley Eastern Ltd. 
Gharti Chhetri, P.S. (2005). Factors associated with Malnutrition among Children in Rural Terai of Eastern Nepal (Master's dissertation, Achutha Menon Centre for Health Science Studies, Sree Chitra Tirunal Institute for Medical Sciences and Technology). Retrieved from http://dspace.sctimst.ac.in/jspui/bitstream/I23456789/2096///MPH_2005_07.pdf

Ghimire, M.N. (20/4). Health status of children of Chepang and other communities of Nepal. Journal of Advanced Academy Research (JAAR), I(I), 24-28. Retrieved from https://shodhganga.inflibnet.ac.in/bitstream//0603//93404//7/17_publications.pdf

Hosmer, D.W., \& Lemeshow, S. (2000). Applied Logistic Regression. New York: Wiley.

Hosmer, D. W., \& Lameshow, S. (1980). Goodness of fit tests for the multiple logistic regression model. Communications in Statistics - Theory and Methods, 9(10), 1043-1069.

International Food Policy Research Institute (2016). Global nutrition report from promise to impact ending malnutrition by 2030. Retrieved from http://ebrary.ifpri.org/utils/getfile/collection/p 15738coll2/id// 30354/filename//30565.pdf

Ministry of Health (2017). Nepal Demographic and Health Survey 2016. Retrieved from https://www.dhsprogram.com/pubs/pdf/fr336/fr336.pdf

Nagelkerke, N.J.D. (1991). A note on a general definition of the coefficient of determination, Biometrika, 78: 691-692. Retrieved from https://doi.org// 0.1093/biomet/78.3.69I

Pokhrel, A.U., Parajuli, S., \& Acharya, A. (2018). Prevalence and associated factors of undernutrition among under-five children of Bharatpur Municipality of Chitwan district. Nepal Birat Journal of Health Sciences, 2(3), 266-272.

doi: https://doi.org/ | 0.3 | 26/bjhs.v2i3. I894 |

Ruwali, D. (2018). Nutritional status of children under five years of age and factors associated in Padampur VDC, Chitwan. Health Prospect: Journal of Public Health, 10, $14-18$. doi: https://doi.org//0.3/26/hprospect.v10i0.5639

Shah, R.K. (2014). Sociological field-trip of Chepang community. Retrieved from http: //www.slideshare.net/RamKumarshah/report-on-chepang-community-of-shaktikhorchitwan-nepal

Upadhyay, H.P. \& Bhusal, M. K. (2017). Statistical analysis on nutritional status and its associated factors of under five years children in Nepal. Advanced Journal of Graduate Research, 2(I), 12-24. doi: https://doi.org//0.21467/ajgr.2.1.12-24

World Food Program (2005). A Manual: Measuring and Interpreting Malnutrition and Mortality. Retrieved from https://www.unhcr.org/45f6abc92.pdf

World Health Organization (2009). WHO child growth standards and identification of severe acute malnutrition in infants and children, A Joint statement by World Health Organization and the United Nations Children's Fund. Retrieved from https://apps.who.int/iris/bitstream/handle//0665/44 I 29/978924 I598I63_eng.pdf?ua= I World Health Organization (2017). World Health Organization malnutrition fact sheet. 
Reference to this paper should be made as follows:

Poudel, R. K., \& Khanal, S. P. (2020). Binary logistic regression model for assessing factors associated with nutritional status of children under five years among Chepang community in Siddi, Chitwan, Nepal. Nep. J. Stat, 4, 43-56. 